\title{
Home moves and child wellbeing in the first five years of life in the United States
}

\author{
Brenden Beck The Graduate Center, City University of New York \\ bbeck@gradcenter.cuny.edu \\ Anthony Buttaro, Jr. The Graduate Center, City University of New York \\ Mary Clare Lennon The Graduate Center, City University of New York
}

(Received September $2015 \quad$ Revised March 2016)

http://dx.doi.org/10.14301/Ilcs.v7i3.374

\section{Abstract}

By the time they are five years old, nearly $70 \%$ of children in the United States have moved home, with a substantial minority moving more than once. These early years are important for children's later learning and development. Yet, there are a limited number of studies of residential mobility's impact on young children. The literature indicates the importance of stressful family events, unstable housing, economic hardship, and neighbourhood conditions for residential mobility and child wellbeing. But research seldom examines the impact of these dimensions simultaneously. We used data from the first four waves of the Fragile Families and Child Wellbeing Study to analyse precursors of residential mobility and the association of residential mobility with child behavior $(N=2,511)$ and cognitive capabilities $(N=2,033)$ at age five. Using Generalized Estimating Equations (GEE), we find that the frequency of moving is explained by a range of stressful circumstances, including lack of parental employment, partnership transitions, paternal incarceration, unstable housing tenure, and financial hardship. These circumstances are associated with increased likelihood of moving home even when other family and neighbourhood conditions are controlled, suggesting that moving is part of a constellation of events and changes experienced by young children. Using OLS regression models we find that, for young children, the circumstances associated with moving residence appear to be more consequential for child wellbeing than does moving itself, even when children experience multiple moves.

\section{Keywords}

Residential mobility, child development, early years, Fragile Family and Child Wellbeing Study, Generalized Estimating Equations

\section{Introduction}

In this paper, we examine the precursors of residential mobility among young children and the relationship between residential moves and child behaviour problems and cognitive skills. There is little research on this topic, even though the United States has particularly high rates of home moves among very young children. According to the 2000 Current Population Survey (chosen because it coincides with our data on children), almost one in four (23.3\%) children aged zero-four had moved home in the year prior to March 2000 (US Census Bureau 2001). Although the Census does not report data on multiple moves, research finds that these are common as well, 
especially among low-income children (Jelleyman \& Spencer, 2008).

\section{Precursors of residential mobility}

Changing residence does not occur at random. Families move for various reasons, primarily due to life course changes, such as the birth of a new child or the formation of a new household partnership. Some of these changes are the result of difficult circumstances, such as marital separation or unemployment. Studies of the consequences of residential mobility for child wellbeing often treat the conditions that promote home moves as 'nuisance factors', variables that must be controlled to estimate the true causal effect of mobility. Sampson and Sharkey $(2008$, p. 1) note that researchers tend to see such processes of selection as "a statistical problem to be controlled away and not something of substantive interest in itself." And yet, the circumstances in family life that may lead to home moves are of great interest as they represent important sources of family stress and opportunity. Building on a recent paper by Anderson, Leventhal, Newman and Dupéré (2014) that draws attention to the context in which residential mobility occurs in childhood, we examine the circumstances in family life that precede home moves and that may, independent of moves, be a source of stress for families. We hypothesise that any negative association of residential moves with child wellbeing is accounted for by events and conditions that precede home moves rather than by moving per se.

\section{Residential mobility and child wellbeing}

Studies of residential mobility and child wellbeing are often framed within Bronfenbrenner's ecological systems perspective that emphasises the interrelationships among the developing child and the multiple contexts within which development occurs (Bronfenbrenner, 2005; Bronfenbrenner \& Evans, 2000; Bronfenbrenner \& Morris, 2006). Development is a process that unfolds as children interact with contexts that range from immediate (e.g., family) to more remote (e.g., culture). Contexts that are more proximal to the child, such as home, school, and peer group, are thought to be of more direct influence on development, since the child's daily activities and interactions are embedded in these arenas.
Using this framework, some scholars have suggested that residential mobility harms children to the extent that it disrupts family routines, educational progress, social networks and peer relationships. These disruptions contribute to poor child health and mental health outcomes (e.g., Anderson, Leventhal, Newman, \& Dupéré, 2014; Astone \& McLanahan, 1994; Stokols, Shumaker, \& Martinez, 1983; ZiolGuest \& McKenna, 2014). Our study takes a somewhat different perspective, by first investigating the disruptions that occur within families prior to residential moves and then examining the consequences of both these disruptions and moving for children. We suspect that, for young children, the circumstances associated with moving residence may be more consequential for their wellbeing than is moving itself, even when children experience multiple moves. These circumstances include changes in family structure and parental employment, unstable housing tenure, and financial hardship, all of which contribute to residential mobility and adverse child outcomes.

Our study brings together Bronfenbrenner's theories with insights from social stress theory. (Brown \& Harris, 1978; Dohrenwend \& Dohrenwend 1969; George, 1989; 1993; Holmes \& Rahe, 1967; Thoits 1983). According to social stress theory, stressful life events require readjustment on the part of individuals, at times, taxing their ability to cope. Early research posited that any change, positive or negative, could be stressful (Holmes \& Rahe, 1967) but later studies have shown that negative change, such as divorce, is especially detrimental to psychological wellbeing (Brown \& Harris, 1978; Thoits, 1983). In considering effects on children, the family stress model posits that a parent's capacity to interact positively with her or his child may be undermined when the parent is exposed to stressful conditions (Conger \& Elder, 1994). Ultimately, children in such circumstances often develop behavioural and school problems.

Some researchers view home moves as stressful events that have potential negative impacts on children. These studies generally find that residential mobility is associated with behavioural problems, adverse mental and physical health, and lower academic performance (Jelleyman \& Spencer, 2008; Mehana \& Reynolds, 2004; Pribesh \& Downey, 1999; 
Scanlon \& Devine, 2001), with frequent moves thought to be most detrimental for children (Jelleyman \& Spencer, 2008). Research suggests that such effects are particularly strong among children from households with low income (Scanlon \& Devine, 2001). However, when investigators control for a range of background characteristics, some find that 'effects' of mobility may be fully or partly accounted for by these characteristics (e.g., Anderson, 2012; Wood, Halfon, Scarlata, Newacheck, \& Nessim, 1993), suggesting that selection into moving may drive some of the negative associations of child outcomes with residential mobility. In this paper, we investigate whether moves have negative effects on young children's wellbeing independent of the precursors of moving.

Early childhood is a stage in which children experience rapid and foundational changes for future growth and learning (Phillips \& Shonkoff, 2000). Yet, it has not been established whether moving during this time period has consequences for children. The physical growth and brain development occurring during early childhood pair with the increase in motor, language and emotional skills: children learn to direct their attention, control their behaviour, interact with others in an orderly way, and begin to form attachment bonds with people and places. As family stress theory suggests, home moves might affect young children through disruptions in their parents' and siblings' lives and social networks. Moreover, because of the cumulative nature of learning, moves occurring before age five could have an impact on school readiness. On the other hand, it is also possible that such cumulative learning includes the skills of adaptation and resilience that will allow the child to mitigate or prevent the consequences of adversities (Masten et al., 2012).

Given this, it is surprising that there are so few studies of younger children compared to the numerous studies of school-age children. There are even fewer based on national samples or longitudinal data. Results of the existing studies diverge from both the school-age literature and from one another. Some research indicates that residential mobility in the early years does not have an impact on cognitive or academic ability (Anderson, 2012; Coley, Leventhal, Lynch, \& Kull 2013; Stoneman, Brody, Churchill, \& Winn, 1999; Ziol-Guest \& McKenna,
2014). This finding is inconclusive, however, as studies generally rely on small (e.g. Stoneman et al., 1999) or unrepresentative (e.g., Anderson, 2012) samples. Diverging from the other studies, Schmitt, Finders, \& McClelland (2015) do find mobility is negatively associated with achievement in the fall term of pre-school in a sample of children primarily from Head Start. They find an indirect impact of mobility on spring achievement via fall achievement. Such mediating effects of early academic achievement suggest, along with previous research, that early years learning may have a cascade effect on later school performance (Phillips \& Shonkoff, 2000).

When examining emotional and behavioural outcomes, researchers have found limited effects of residential mobility. Some find that externalising and internalising behaviours are not associated with residential moves (Anderson 2012; Murphey, Bandy \& Moore 2012). Ziol-Guest \& McKenna (2014)' report that attention problems, internalising behaviour and externalising behaviour are higher among children who moved three or more times and were also poor, compared to other young children. Studying a lowincome population of young children, Stoneman and colleagues (1999) find that problem behaviours and depression were associated with frequent moves only among children whose temperaments were characterised by low emotional intensity. Using threelevel hierarchical linear models and a sample from low-income urban areas, Coley and colleagues (2013) find negative effects of residential mobility on behaviour problems between individuals (i.e., moving is associated with more problems) but positive effects within individuals (i.e., moving is associated with fewer problems), suggesting possible selection processes at work. These associations hold in both early childhood and adolescence. As with studies of cognitive achievement, studies of behaviour generally rely on small and unrepresentative samples, although more recent work does use larger samples and longitudinal data (e.g., Ziol-Guest \& McKenna, 2014).

\section{Childhood residential mobility in context}

We argue that moving home might not reduce wellbeing on its own, but may do so because it cooccurs with stressful events like marital dissolution, job loss or financial hardship. For young children, 
home moves often follow stressful family events such as parental incarceration, marital separation and unemployment (Clark, 2016, this issue; Clark 2012; Clark \& Davies Withers, 1999; Geller, Garfinkel, Cooper, \& Mincy, 2009; Long, 1992a), which diminish family economic resources. While these family events may undermine the wellbeing of children in general, economic hardship is especially detrimental for younger children (see, for example, Duncan, BrooksGunn, \& Kato Klebanov, 1994; Gershoff, Aber, Raver, \& Lennon, 2007). Moreover, for some children, moving house is a direct result of economic hardship and, at times, moving is involuntary (Clark, 2016, this issue; Long, 1992b; Phinney, 2013). Recent studies by Desmond, Gershenson, and Kiviat (2015) and Phinney (2013) highlight the importance of residential instability and evictions for children and families.

In sum, the literature indicates the importance of stressful family events, unstable housing, and economic hardship for residential mobility and its outcomes. But research seldom examines the impact of these dimensions simultaneously. And yet, the literature suggests the value of this joint analysis. First, these dimensions of children's lives are linked to each other. Changes in family structure affect residential mobility: children whose parents separate or divorce are highly likely to experience residential moves (Astone \& McLanahan, 1994; South, Crowder \& Trent, 1998), as are children whose parents become unemployed or change jobs (Clark \& Davies Withers, 1999) or become incarcerated (Geller \& Franklin, 2014). Second, overlapping mechanisms underlie the impact of each dimension on child wellbeing. Family transitions and residential mobility compromise child wellbeing to the extent they increase economic hardship, reduce the quality of social relationships, heighten family stress, and damage maternal mental health (Astone \& McLanahan, 1994; Pribesh \& Downey, 1999; Yeung, Linver, \& Brooks-Gunn, 2002).

Put together, these studies suggest the importance of examining the precursors as well as the consequences of residential mobility for young children's wellbeing and development. Specifically, we predict that disruptions in families (including partnership transitions, parental incarceration, changes in parental employment, and instability of housing tenure) will be associated with home moves over time among young children. We expect further that effects of residential mobility on child wellbeing depend, in part, on the circumstances that precede mobility. This overarching framework integrates a family stress perspective with an ecological model. By combining these, we gain the former's emphasis on stress throughout childhood and on linked lives (Elder, Johnson, \& Crosnoe, 2003) with the latter's focus on the multiple contexts in which child development unfolds, specifically in families and neighbourhoods (Bronfenbrenner, 1977 and 1986).

\section{Data}

We used restricted, non-public data from the first four waves of the Fragile Families and Child Wellbeing Study (FFCWS), a longitudinal investigation of 4,898 families with children born between 1998 and 2000 in 20 large US cities, oversampling unmarried parents (Reichman, Teitler, Garfinkel, \& McLanahan, 2001). We focus on early childhood and include data from interviews as well as ecological measures at the time of the child's birth and when children were one, three, and five years old. Interviews were conducted with both the mother and father (when available) of the focal child ${ }^{\mathrm{ii}}$. Besides these core surveys, additional information (e.g. child developmental outcomes, physical environment, parenting, etc.) was collected through in-home interviews with the primary caregiver and child activity assessments. At age five (the wave from which the child outcome measures were taken), 4,139 mothers completed the core questionnaire. Of these, $74 \%$ participated in the home interview and $57 \%$ (of children) in the activities assessment. Because of this non-random selfselection, we chose two analytic samples restricted respectively to 2,511 children with complete data on mobility, residential area disadvantage and behavioural outcomes (part of the in-home interview) and to 2,033 children with complete data also on verbal outcomes (included in the activity assessment component). However, when comparing background and family characteristics between the full and analytic samples, we did not find large differences ${ }^{\text {iii. }}$

To deal with missing data, we employed a twostage strategy that built on both the longitudinal nature of the Fragile Families study and the fact that the information was collected from both mother and 
father of the focal child. In the first stage, whenever applicable, missing information from the mother was logically replaced using either a repeated version of the variables in question, and/or supplementing it with the equivalent item from the father questionnaire. In the second stage, we imputed the remaining missing data via multiple imputation (Rubin, 1987). Multiple imputation (MI) is a simulation-based technique that creates multiple copies of the original data set and replaces missing information in each of these with values predicted from other variables (not necessarily with complete observations). Each imputed data set is analyzed as if it had complete data and the relative vector of parameters and associated variances is estimated. Then, following Rubin's rules, the vector of combined parameters and associated variances is computed, that is: each combined parameter equals the average of the corresponding values across all the multiple data sets; each combined associated variance equals the sum of the 'average within-imputation variance' and the 'between-imputation variance' (Rubin, 1987). The goal of $\mathrm{Ml}$ is not to predict true values but rather to handle missing information in order to produce valid inference (Rubin, 1996). We used the module implemented in Stata 13 to carry out the MI procedure in our analytic sample. We created 20 imputed data sets and, using the univariate method with passive approach, we imputed each single crosssectional variable with missing information separately by the appropriate imputation model (e.g. logit, multinomial, Poisson, etc.) and then created the longitudinal measures ${ }^{\text {iv }}$. We used these augmented data to run the models for the multivariate analyses.

All analyses used the five year-wave city-level probability weights and were adjusted to account for survey design. Moreover, in our longitudinal model, we also adjusted for (the natural logarithm of) time between interviews since the spacing of the surveys varied from child to child and there were some outliers.

\section{Measures}

In the present investigation we used both timevarying and time invariant measures as dependent as well as independent variables. Some of the timevarying measures capture changes occurring between consecutive waves, whereas the others are crosssectional predictors lagged with respect to the dependent variables (tables 1 and 2 specify which contiguous waves the changes refer to and when the data were collected). Moreover, because of our analytic strategy (see below), most of the timevarying measures were also combined into single longitudinal variables. We detail the operational definitions of all measures below.

\section{Dependent Variables}

Number of Moves between Contiguous Waves is the count of residential moves that occurred between consecutive waves of data collection reported by the mother at respectively age one, three, and five. On each measurement occasion the range ran from 'zero moves' through ' 10 moves'. Table 1 gives the average number of moves at each wave. At each time point, the inclusion of stayers brings the average number of moves to below one. Between birth and one year, $34 \%$ of children had moved at least once and between one-three years and three-five years, around $40 \%$ of the children moved at least once (not shown). Because moving four or more times between waves was relatively infrequent (occurring in fewer than $1 \%$ of cases), we recoded these cases by setting the upper limit of this measure to ' $3+$ moves'). 
Table 1. Weighted descriptive statistics: outcome variables

\begin{tabular}{|c|c|c|c|}
\hline Variable & Mean & St. Dev. & Min - Max \\
\hline \multicolumn{4}{|l|}{ Number of moves between: } \\
\hline Birth to age 1 & .43 & .70 & $0-3+$ \\
\hline Age 1 to age 3 & .50 & .68 & $0-3+$ \\
\hline Age 3 to age 5 & .52 & .76 & $0-3+$ \\
\hline \multicolumn{4}{|l|}{ Child outcomes at 5yr: } \\
\hline Vocabulary score ${ }^{1}$ & 94.19 & 16.57 & $40-139$ \\
\hline Externalising behaviour ${ }^{2}$ & .40 & .24 & $0-1.5$ \\
\hline Internalising behaviour & .24 & .20 & $0-1.1$ \\
\hline
\end{tabular}

${ }^{1}$ Based on the Peabody Picture Vocabulary Test (PPVT). It is an age-based standard score with M=100, SD=15 (Dunn \& Dunn, 1997).

${ }^{2}$ The averages of 30 externalising and 22 internalising items on the Child Behavior Checklist (as selected by the FFCWS) scored 0 to 2 (Achenbach, 1992).

Peabody Picture Vocabulary Test (PPVT) is the cognitive measure which assesses children's agestandardised knowledge of receptive vocabulary and comprehension of spoken English. In this test, interviewers asked children to identify a picture (among a set of four pictures) that corresponded to a word that the interviewer read. The PPVT is highly correlated with standardised measures of intelligence such as the Wechsler Intelligence Scale-Third Edition (Dunn \& Dunn 1997). As shown in Table 1, children in the FFCWS cities, even after weighting for the overrepresentation of single mothers, score about 5.8 points lower than the normed average of 100 (normed standard deviation=15).

Internalising behaviour and Externalising behaviour are two scales consisting of the sum of items from the Child Behavior Checklist (CBCL) (Achenbach, 1992; Achenbach \& Rescorla, 2000), administered to caregivers as part of the in-home interview to rate the child on various emotional and behavioural problems at age five. The $\mathrm{CBCL}$ Internalising measure, which encompasses the $\mathrm{CBCL}$ sub-scales 'Anxious/Depressed' and 'Withdrawn', covers emotional problems; the Externalising measure, which instead encompasses the $\mathrm{CBCL}$ sub-scales 'Aggressive' and 'Delinquent', assesses acting-out forms of behavioural problems. Response categories for each item indicated frequency of the problems (' 0 . not true', '1. somewhat or sometimes true', '2. very true or often true'). We took the mean score of 22 internalising and 30 externalising items. Cronbach's alphas for the two scales were respectively .75 and .86. As seen in table 1 , in FFCWS, more externalising than internalising behaviour items are endorsed by the mothers.

\section{Main Independent Variables}

We created two types of longitudinal measures: one set (shown in table 2) captures wave-to-wave changes and is used in analyses of residential mobility; the other (shown in table 3 ) captures changes between birth and age five and are used in analyses of child outcomes.

Partnership change between contiguous waves was created by combining FFCWS-constructed variables indicating the specific family structure at each of two consecutive waves (i.e. mother with child's biological father; mother with partner who is not child's 
biological father; and single mother). The resulting combination was then recoded in a final five-category measure which refers to the changes that occurred between interviews, that is whether the mother had: been stably coupled (i.e. with the same partner at both interviews); transitioned from being in a couple to living with a new partner; transitioned from being single to living with a partner; transitioned from living with a partner to being single; or was single at both time points. As shown in table 2, the proportion of stably coupled women declines at each wave from $68 \%$ between the child's birth and age one, to $60.5 \%$ between age three and five. There is a corresponding increase in proportions who move from coupled to single or who remain single between waves. 
Table 2. Weighted descriptive statistics: time-varying variables

\begin{tabular}{|c|c|c|c|}
\hline \multirow{2}{*}{ Measured between waves } & Birth to year 1 & Year 1 to year 3 & Year 3 to year 5 \\
\hline & Mean (SD) & Mean (SD) & Mean (SD) \\
\hline \multicolumn{4}{|l|}{ Partnership change } \\
\hline Stably coupled biological father (ref.) & $.678(0.47)$ & $.676(0.47)$ & $.605(0.49)$ \\
\hline From coupled to new partner & $.005(0.07)$ & $.014(0.12)$ & $.031(0.17)$ \\
\hline From single to coupled & $.106(0.31)$ & $.063(0.24)$ & $.072(0.26)$ \\
\hline From coupled to single & $.063(0.24)$ & $.098(0.30)$ & $.115(0.32)$ \\
\hline Stably single (no partner at both waves) & $.148(0.36)$ & $.148(0.36)$ & $.177(0.38)$ \\
\hline \multicolumn{4}{|l|}{ Change in paternal incarceration } \\
\hline No incarceration (ref. group) & $.951(0.21)$ & $.941(0.24)$ & $.939(0.24)$ \\
\hline Incarcerated at start of period & $.014(0.12)$ & $.019(0.14)$ & $.019(0.14)$ \\
\hline Incarcerated at end of period & $.030(0.17)$ & $.024(0.15)$ & $.020(0.14)$ \\
\hline Incarcerated at both waves & $.006(0.07)$ & $.016(0.13)$ & $.022(0.15)$ \\
\hline \multicolumn{4}{|l|}{ Transition in HH employment status } \\
\hline Stably employed (ref. group) & $.759(0.43)$ & $.747(0.43)$ & $.737(0.44)$ \\
\hline From out of work to employed & $.075(0.26)$ & $.085(0.28)$ & $.096(0.30)$ \\
\hline From employed to out of work & $.081(0.27)$ & $.088(0.28)$ & $.093(0.29)$ \\
\hline Workless at both waves & $.085(0.28)$ & $.080(0.27)$ & $.074(0.26)$ \\
\hline \multirow{2}{*}{ Measured at a point in time } & Birth & Year 1 & Year 3 \\
\hline & Mean (SD) & Mean (SD) & Mean (SD) \\
\hline \multicolumn{4}{|l|}{ Housing Tenure } \\
\hline Private market rental (ref.) & $.413(0.49)$ & $.376(0.48)$ & $.335(0.47)$ \\
\hline Public housing tenancy & $.118(0.32)$ & $.095(0.29)$ & $.148(0.35)$ \\
\hline Subsidised rental & $.071(0.26)$ & $.072(0.26)$ & $.090(0.28)$ \\
\hline Homeownership & $.252(0.43)$ & $.273(0.45)$ & $.284(0.45)$ \\
\hline Other/shared accommodation & $.145(0.35)$ & $.183(0.39)$ & $.143(0.35)$ \\
\hline Index of local area relative disadvantage & $.795(1.45)$ & $.756(1.44)$ & $.713(1.47)$ \\
\hline Hardship ${ }^{1}$ & $605(0.99)$ & $.561(0.95)$ & $.618(1.00)$ \\
\hline Nat. log of equivalised $\mathrm{HH}$ income ${ }^{1}$ & $9.665(1.50)$ & $9.835(1.45)$ & $9.799(1.37)$ \\
\hline Household size & $4.418(1.67)$ & $4.459(1.61)$ & $4.552(1.56)$ \\
\hline New sibling (or twin/triplet at birth) & $.023(0.15)$ & $.126(0.33)$ & $.367(0.48)$ \\
\hline
\end{tabular}

\footnotetext{
${ }^{1}$ Reported in an interview subsequent to the time period.
} 
Change in paternal incarceration status between waves is the combination of two original dichotomous variables indicating whether, for each of two consecutive time points, the child's biological father was in jail. The four values of the resulting variable indicate whether he was: never incarcerated from beginning to end time point, incarcerated just at the beginning time point, incarcerated at the end time point, or incarcerated throughout the whole time. About $5-6 \%$ of fathers were incarcerated at each interview.

Transition in household employment status between waves is a four-category variable indicating change in the employment of the mother and her partner within each household across contiguous waves. At the baseline wave, we considered a mother as 'employed' if she had a job at the time of the interview or if her last job terminated no longer than six months prior to the birth of the child. For the child's father or the mother's partner, we considered his employment status at each wave s/he lived with the child's mother. We considered the household as 'employed' at a given interview if the mother (or the partner if she had one) reported having worked at a regular job most of the previous week. We constructed an employment transition measure with the following categories: household 'stably employed', 'from out of work to employed', 'from employed to out of work' and 'out of work throughout'. As seen in table 2, about three in four households reported at least one person working between each of the waves.

Housing tenure before moving reports the type of tenancy that child's mother had at the wave preceding any residential move (i.e., at birth, one year and three years). It is a five-category variable (' 1 . private market rental', '2. public housing tenancy', ' 3 . subsidised rental', '4. homeownership', and '5. other/shared accommodation') $)^{v}$. As shown in table 2 , the modal tenancy at each wave is market rental (without subsidy), followed by homeownership.

Index of local area relative disadvantage is a composite score created by Principal Component Analysis (PCA) based on a set of seven variables from the 2000 US Census measuring different aspects of socioeconomic disadvantage (proportion of: people below poverty level, people at least 16 years old who are unemployed, households receiving welfare, female-headed households, people aged 25 or older with no high school diploma) and advantage (proportion of: people aged 25 or older with college degree and people at least 16 years of age who are managerial/professional workers) of the census tract of residence (Wodtke, Harding, \& Elwert, 2011). The index was created at the national level on a total of almost 65,000 US census tracts. Its semantic polarity is such that higher scores indicate higher levels of local area disadvantage. The index was then merged to each of the four waves of the FFCWS data and used in the multivariate models.

Level of hardship is a sum of five items referring to possible problems encountered up to twelve months before each follow-up interview because of scarcity of money (i.e. receiving free food/meals, not being able to pay full rent/mortgage, not paying full amount utilities bills, borrowing money from friends/family, not seeing doctor/going to hospital because of money problems). We selected these items because they were asked consistently over time in the surveys at age one, three and five.

In analyses of child outcomes, the primary independent variable is Total number of moves from birth through five-year wave. This is the sum of the counts of residential moves that occurred between consecutive waves (see above). Because of outliers and to establish linearity in the parameters, it was recoded to a range from 'zero moves' through 'five or more moves'vi. The distribution of moves is shown in table 3 . Only $31 \%$ of families had not moved at all between the child's birth and fifth birthday; a similar percent moved only once. Multiple moves are common, with $18.6 \%$ having moved twice and another $19.9 \%$ moving three or more times. This is in stark contrast to the MCS statistics reported by Gambaro \& Joshi (2016, this issue) who found that only $5 \%$ of the U.K. cohort moved three or more times (albeit in a somewhat shorter time frame of nine months to five years). 
Table 3. Weighted descriptive statistics: time-invariant variables

\begin{tabular}{|c|c|c|c|}
\hline Variable & Mean & St. Dev. & Min - Max \\
\hline \multicolumn{4}{|l|}{ Number of moves, birth-5yr } \\
\hline 0 & .310 & .46 & $0-1$ \\
\hline 1 & .305 & .46 & $0-1$ \\
\hline 2 & .186 & .39 & $0-1$ \\
\hline 3 & .100 & .30 & $0-1$ \\
\hline 4 & .050 & .22 & $0-1$ \\
\hline $5+$ & .049 & .22 & $0-1$ \\
\hline \multicolumn{4}{|l|}{ Partnership change, birth-5yr } \\
\hline Stably coupled with biological father (ref. group) & .519 & .50 & $0-1$ \\
\hline From coupled to new partner & .040 & .20 & $0-1$ \\
\hline From single to coupled & .084 & .28 & $0-1$ \\
\hline From coupled to single & .129 & .34 & $0-1$ \\
\hline Multiple transitions & .146 & .35 & $0-1$ \\
\hline Stably single & .082 & .27 & $0-1$ \\
\hline \multicolumn{4}{|l|}{ Paternal incarceration, birth-5yr } \\
\hline Never incarcerated & .914 & .28 & $0-1$ \\
\hline Incarcerated before birth & .019 & .14 & $0-1$ \\
\hline Incarcerated after birth & .067 & .25 & $0-1$ \\
\hline \multicolumn{4}{|l|}{ Household employment status, birth-5yr } \\
\hline Stably employed (ref. group) & .646 & .48 & $0-1$ \\
\hline From out of work to employed & .081 & .27 & $0-1$ \\
\hline From employed to out of work & .086 & .28 & $0-1$ \\
\hline In and out of work ( 2 or 3 changes) & .164 & .37 & $0-1$ \\
\hline Stably workless & .023 & .15 & $0-1$ \\
\hline Household was ever evicted, birth-5yr & .041 & .20 & $0-1$ \\
\hline Index of local area relative disadvantage at 5yr & .603 & 1.45 & $-2.0-4.9$ \\
\hline Index of local area relative disadvantage at birth & .795 & 1.45 & $-2.0-4.9$ \\
\hline Average level of hardship, $1-5 y r$ & .593 & .77 & $0-5$ \\
\hline Child has had new siblings, birth-5yr & .397 & .49 & $0-1$ \\
\hline Child was firstborn & .381 & .49 & $0-1$ \\
\hline Mother was not born in US & .215 & .41 & $0-1$ \\
\hline \multicolumn{4}{|l|}{ Mother's race/ethnicity } \\
\hline White (ref. group) & .302 & .46 & $0-1$ \\
\hline Black & .361 & .48 & $0-1$ \\
\hline Hispanic & .277 & .45 & $0-1$ \\
\hline Other race/ethnicity & .060 & .24 & $0-1$ \\
\hline Mother's age in years at birth wave & 27.1 & 6.15 & $14-47$ \\
\hline Mother's level of education at birth wave & 4.0 & 1.66 & $1-7$ \\
\hline Mother's level general health at $1 \mathrm{yr}$ wave & 3.9 & 1.06 & $1-5$ \\
\hline Mother depressed at $1 \mathrm{yr}$ wave & .098 & .30 & $0-1$ \\
\hline Child's biological sex is male & .571 & .49 & $0-1$ \\
\hline Child was born underweight & .091 & .29 & $0-1$ \\
\hline Child's general health at $1 \mathrm{yr}$ & 4.5 & .78 & $1-5$ \\
\hline
\end{tabular}




\begin{tabular}{cccc} 
Variable & Mean & St. Dev. & Min - Max \\
\hline Child's age in months at 5yr & 60.6 & 2.37 & $56-71$ \\
\hline
\end{tabular}

The main explanatory variables for analyses of child outcomes are shown in table 3. A longitudinal indicator Partnership change from child's birth through five-year wave was created from the between wave transitions. Since this variable accounts for the transitions that occurred across all four waves of data, an additional category 'multiple transitions' was added. A dummy variable that captures whether or not the father was incarcerated at or since the child's birth was included as well. In addition, we created the longitudinal predictor Transition in household employment status from child's birth through five-year wave which records the transitions across all four waves and adds the category 'in and out of work' to capture multiple employment transitions. We include an indicator of eviction (any report of eviction in waves 1, 3 and 5), housing tenure at birth, and local area disadvantage at birth and at age five. The Average level of hardship from child's birth through five-year wave was computed by averaging the three measures of hardship described above across waves.

\section{Control Variables}

Natural logarithm of equivalised income is the time-varying measure used to represent household income in the year before the interviews took place. We equivalise the original income measure by weighting it according to household size and composition (i.e. number of children vs number of adults) using the formula proposed by McClements (1977). This equivalised measure then accounts for the cost of living across households. Moreover, to limit the effect of outliers we used the natural logarithm of this new measure. We include income and mother's education to capture the influence of socioeconomic status on mobility and child outcomes which research has routinely documented (Leventhal \& Newman, 2010; Long 1992b; Mehana \& Reynolds 2004).

Household size is the number of individuals living in the household, including the respondent; and New siblings indicates whether after the focal child's birth new siblings became part of the household ('0. no' and '1. yes'). At baseline we assigned value '1. yes' if the mother had had twins or triplet. At ages one and three we combined information from a question about whether the mother had another baby or was pregnant at the time of the interview and from the addition of a new child on the household roster ('Biological/Adopted child', 'Stepchild', 'Foster child'). New siblings from child's birth through five-year wave indicates whether or not any new sibling became part of the household over that period. We also created a dummy variable, Child was first born, to indicate whether the focal child was the oldest among the coresident siblings. These household characteristic variables control for family growth that might affect space needs, precipitate moves, and change the ecological context of child outcomes.

Finally, we also included in the multivariate models a series of time-invariant controls available at either baseline or age one. They can be grouped into measures about: the mother (i.e. mother was not born in US, race/ethnicity, age, level of education, level of general health at one-year wave, depressed at one-year wave vii); and the child (biological sex is male, low birthweight as below 2,500 gm, level of general health at one year, age in months at five-year wave). Further details about all the variables can be found in table 3. A wide range of research has found mother's race/ethnicity to be an influence on residential mobility (Anderson 2012, p. 84; Coulton, Theodos, \& Turner, 2009; Desmond 2012; Long 1992 b, p. 866). As discussed in the literature review, maternal health is closely linked with child outcomes (Cicchetti, Rogosch, \& Toth, 1998; Lyons-Ruth, Brofman \& Parsons, 1999) and mobility (Anderson et al., 2014), which motivates our inclusion of these variables.

\section{Analytic strategy}

We conducted the multivariate analysis using two different modelling techniques. To address the question about the precursors of residential mobility we modeled the number of residential moves over time by Generalized Estimating Equations (GEE). The main advantage of this technique over generalised linear models is the ability to account for withinsubject correlation among the repeated measures (Hilbe, 2014). Such correlation structure can be further specified as independent, exchangeable, 
autoregressive, or unstructured, although some authors emphasise the robustness of GEE models even with a mis-specified correlation structure (Fitzmaurice, Laird, \& Ware, 2011). To choose the most appropriate specification, we compared the zero-level correlations of the repeated measures of the dependent variable with the post-GEE estimation of the within-subject correlations for three different correlation structure specifications of the model (i.e. autoregressive, exchangeable and unstructured). We found the greatest similarity with the correlations obtained after the run of the GEE with a first order autoregressive specification (i.e. AR1). This means that the value of the outcome (number of moves) is more highly correlated with its immediately preceding value, but progressively less the earlier the time points its (time-varying) values belong to. In addition, because our dependent variable did not show over-dispersion, we chose the Poisson model link for the final specification. We ran two GEE models: the first, with family events and circumstances; in the second, we included all the controls.

To investigate the consequences of residential mobility for child wellbeing we ran separate series of Ordinary Least Squares (OLS) regression models to predict each of the three child outcomes of interest (PPVT, and internalising and externalising behaviour). The goal is to test (a) whether there is any baseline association between number of moves and the dependent variables, and (b) whether this association is explained away by the different family events (i.e. change in family configuration, change in household employment status), housing related measures, family vulnerabilities and capabilities, and demographics. Therefore, for each dependent variable we ran a total of five models where the first includes the total number of moves controlling just for child's sex and exact age at the age five interview viii, and the following models add progressively (2) partnership and incarceration (3) employment transitions (4) tenure, eviction, area disadvantage, and hardship (5) all controls (for more details, see table 6 below).

\section{Results}

\section{The precursors of residential mobility}

Table 4 gives results of Generalized Estimation Equations (GEE) predicting number of moves between waves for equations with measures entered sequentially. Model 1 shows coefficients for changing family characteristics, including partnership change, paternal incarceration, parental employment changes, housing tenure, local area disadvantage, and hardship, while Model 2 includes all control variables shown in the bottom half of table 4 . We report both logistic coefficients and exponentiated ones (IRR: Incidence Rate Ratios). The latter indicates the percentage change in the rate of moving associated with a one-unit increase in the predictor variable.

Table 4. Generalised estimating equations with poisson distribution predicting number of residential moves

\begin{tabular}{|c|c|c|c|c|}
\hline \multirow{2}{*}{ Variable } & \multicolumn{2}{|c|}{ Model 1} & \multicolumn{2}{|c|}{ Model 2} \\
\hline & b (SE) & IRR & b (SE) & IRR \\
\hline \multicolumn{5}{|l|}{ Partnership change } \\
\hline Stably coupled (ref. group) & - & - & - & - \\
\hline From coupled to new partner & $.64(.19)^{* *}$ & 1.90 & $.63(.19)^{* *}$ & 1.88 \\
\hline From single to coupled & $.29(.09)^{* *}$ & 1.34 & $.24(.09)^{* *}$ & 1.27 \\
\hline From coupled to single & $.29(.11)^{* *}$ & 1.33 & $.28(.11)^{* *}$ & 1.32 \\
\hline Stably single & $.02(.08)$ & 1.02 & $-.04(.08)$ & .96 \\
\hline \multicolumn{5}{|l|}{ Paternal incarceration } \\
\hline No incarceration (ref. group) & - & - & - & - \\
\hline Incarceration at start & $.26(.12)^{*}$ & 1.30 & $.27(.12)^{*}$ & 1.31 \\
\hline
\end{tabular}




\begin{tabular}{|c|c|c|c|c|}
\hline \multirow{2}{*}{ Variable } & \multicolumn{2}{|c|}{ Model 1} & \multicolumn{2}{|c|}{ Model 2} \\
\hline & b (SE) & IRR & b (SE) & IRR \\
\hline Incarceration at end & $.24(.14)^{\dagger}$ & 1.27 & $.23(.12)^{\dagger}$ & 1.26 \\
\hline Incarcerated throughout & $.20(.15)$ & 1.22 & $.15(.13)$ & 1.17 \\
\hline \multicolumn{5}{|l|}{ Household employment status } \\
\hline Stably employed (ref. group) & - & - & - & - \\
\hline From out of work to employed & $.01(.09)$ & 1.01 & $.05(.09)$ & 1.05 \\
\hline From employed to out of work & $.12(.11)$ & 1.13 & $.15(.12)$ & 1.16 \\
\hline Stably workless & $.16(.11)$ & 1.17 & $.23(.12)^{*}$ & 1.25 \\
\hline \multicolumn{5}{|l|}{ Housing tenure } \\
\hline Private market rental (ref. group) & - & - & - & - \\
\hline Public housing tenancy & $-.38(.15)^{*}$ & .68 & $-.32(.15)^{*}$ & .73 \\
\hline Subsidised rental & $-.22(.11) \dagger$ & .80 & $-.17(.11)$ & .84 \\
\hline Homeownership & $-1.18(.13)^{* * *}$ & .31 & $-1.10(.13)^{* * *}$ & .33 \\
\hline Other/shared tenancy & $-.20(.07)^{* *}$ & .82 & $-.24(.07)^{* *}$ & .78 \\
\hline Index of local area relative disadv. birth & $-.02(.03)$ & .98 & $.00(.03)$ & 1.00 \\
\hline Hardship & $.13(.03)^{* * *}$ & 1.14 & $.11(.03)^{* *}$ & 1.11 \\
\hline Nat. log of equivalised $\mathrm{HH}$ income & - & - & $.04(.02) \dagger$ & 1.04 \\
\hline Household size & - & - & $-.02(.02)$ & .98 \\
\hline Child was first born & - & - & $.13(.08)^{* *}$ & 1.14 \\
\hline New sibling & - & - & $-.26(.09)^{* *}$ & .77 \\
\hline Mother was not born in US & - & - & $.11(.13)$ & 1.12 \\
\hline \multicolumn{5}{|l|}{ Mother's race/ethnicity } \\
\hline White (ref. group) & - & - & - & - \\
\hline Black & - & - & $-.19(.11)^{\dagger}$ & .83 \\
\hline Hispanic & - & - & $-.13(.13)$ & .88 \\
\hline Other race/ethnicity & - & - & $.20(.17)$ & 1.22 \\
\hline Mother's age & - & - & $-.03(.01)^{* * *}$ & .97 \\
\hline Mother's level of education & - & - & $.02(.03)$ & 1.02 \\
\hline Mother's level of general health & - & - & $.02(.04)$ & 1.02 \\
\hline Mother depressed & - & - & $.32(.09)^{* * *}$ & 1.37 \\
\hline Child's biological sex is male & - & - & $-.01(.05)$ & .99 \\
\hline Child was born underweight & - & - & $.12(.07)$ & 1.12 \\
\hline Child's general health & - & - & $.01(.04)$ & 1.01 \\
\hline Constant & $-1.46(.42)^{* *}$ & .23 & $-1.35(.64)^{*}$ & .26 \\
\hline
\end{tabular}




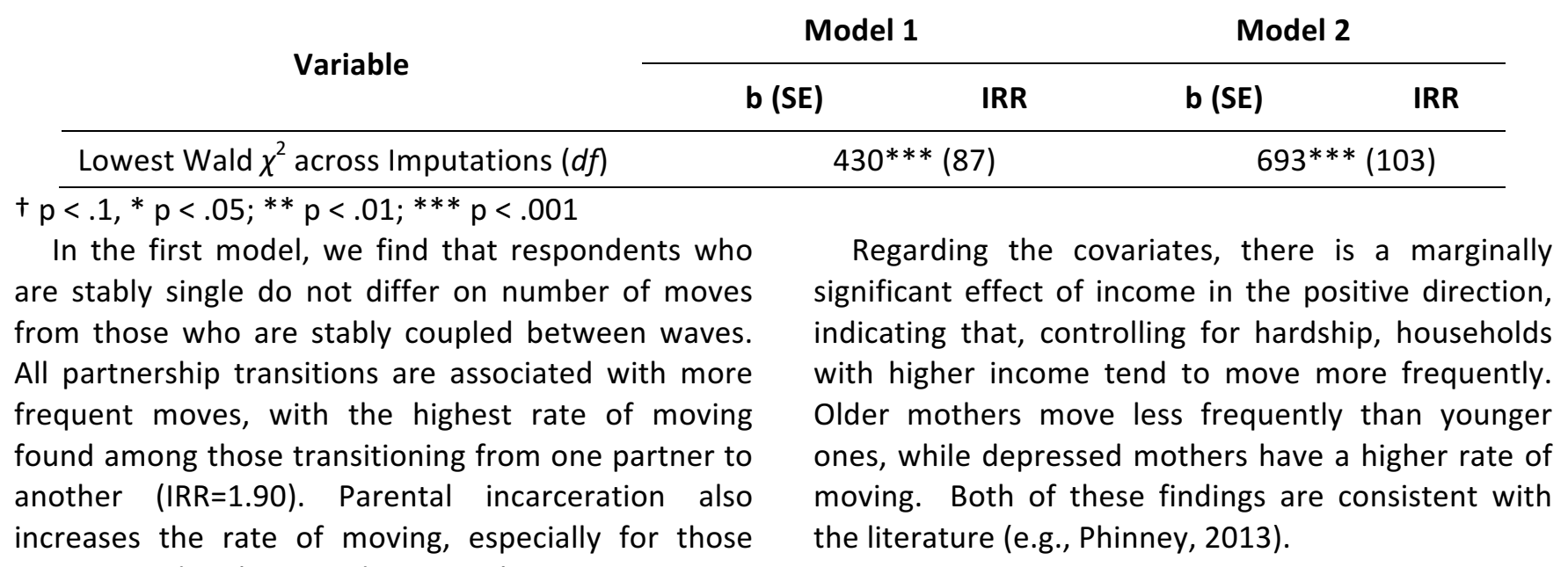
incarcerated in the period prior to the move. Housing tenure is associated with moving frequency, with those living in private market rentals moving more often than residents in other tenures. Homeowners move the least $169 \%$ below the rate of renters in the private market), while those in public housing move at $32 \%$ below the rate found in private renters. Renters in subsidised housing move at $20 \%$ below the rate of private renters, but this estimated parameter is just marginally significant. Each unit increase in hardship on the 0-5 scale increases the rate of moving by $14 \%$.

The second model shows further minor changes in most of the coefficients in model 1 . The coefficient for worklessness increases and becomes statistically significant. Respondents who are out of work at two consecutive time points have a $23 \%$ higher rate of moving compared to those whose household is employed at both times. The coefficient for subsidised rental is no longer statistically significant.

\section{Residential mobility and child outcomes}

Table 5 summarises results of five sequential OLS models for each child outcome (verbal skills, internalising problems, and externalising problems). For each outcome, we find a significant association of number of residential moves from birth through age five in the first model (with few controls) and, in each case, these associations are reduced to nonsignificance with the addition of other variables. The coefficient of verbal skills on number of moves in model 1 is reduced by more than half with the inclusion of partnership transitions and incarceration, and remains non-significant in models 2 through 5 . The coefficient of internalising problems reduces more gradually in models 2 and 3 becoming nonsignificant in models 4 and 5 . The coefficient of externalising problems on number of moves remains significant in models $1-3$, only becoming nonsignificant in the final model. 
Table 5. Regression coefficients for number of residential moves for different model specifications predicting child outcomes

\begin{tabular}{|c|c|c|c|}
\hline \multirow{2}{*}{ Variable } & Verbal score & Internalising problems & Externalising problems \\
\hline & b (SE) & b (SE) & b (SE) \\
\hline Model 1: Family structure at birth, child's sex and age & $-1.28(.45)^{* *}$ & $.015(.006)^{*}$ & $.020(.008)^{*}$ \\
\hline $\begin{array}{l}\text { Model 2: Model } 1 \text { with partnership change, parental } \\
\text { incarceration }\end{array}$ & $-.58(.44)$ & $.014(.007)^{*}$ & $.017(.008)^{*}$ \\
\hline Model 3: Model 2 with employment transitions & $-.47(.42)$ & $.013(.007)^{\dagger}$ & $.016(.008)^{*}$ \\
\hline $\begin{array}{l}\text { Model 4: Model } 3 \text { with housing tenure, eviction, local } \\
\text { area relative disadvantage at birth and } 5 y \text { rs, hardship }\end{array}$ & $-.10(.59)$ & $.007(.007)$ & $.014(.007)^{\dagger}$ \\
\hline Model 5: Full model (see table 6 for all variables) & $-.44(.55)$ & $.008(.008)$ & $.012(.008)$ \\
\hline
\end{tabular}

$+p<.1, * p<.05 ; * * p<.01 ; * * * p<.001$ 
It is worth pointing out that the pattern of results shown in table 5 is very similar to that shown by Gambaro and Joshi for children in the UK Millennium Cohort study (2016, this issue, see table 4). Similar sets of controls reduce the association of moves with child outcomes in both cases (although there are some differences in variables included by each study and some differences in the estimates for each variable). Future work will offer a direct comparison of results of these two studies.

Table 6 shows the final, full model (model 5) for each outcome variable. Even with all control variables in the equation, parental employment remains associated with verbal skills. Compared to children in stably employed families, those whose parents are stably workless or move into or out of employment, have lower reading skills. However, while the coefficient for stably workless households is fully statistically significant, the coefficients for the other two categories of households are only marginally significant. Also, children residing in public housing have lower vocabulary levels than those who are in private rentals. Income, but not hardship, is associated with verbal skills, with children from higher income families performing better. Consistent with this, children with more highly educated mothers and healthier mothers perform better. Both immigrant and minority children have lower verbal scores. 
Table 6. Regression coefficients for full models predicting child outcomes

\begin{tabular}{|c|c|c|c|}
\hline \multirow{2}{*}{ Variable } & Verbal score & Internalising problems & Externalising problems \\
\hline & b (SE) & b (SE) & b (SE) \\
\hline Number of moves & $-.44(.55)$ & $.008(.008)$ & $.012(.008)$ \\
\hline \multicolumn{4}{|l|}{ Partnership change } \\
\hline Stably coupled (ref. group) & - & - & - \\
\hline From coupled to new partner & $-9.22(5.25) \dagger$ & $.013(.052)$ & $-.019(.040)$ \\
\hline From single to coupled & $1.67(2.55)$ & $.035(.033)$ & $.032(.038)$ \\
\hline From coupled to single & $-2.69(2.17)$ & $.017(.022)$ & $.024(.030)$ \\
\hline Stably single & $-1.38(2.29)$ & $.051(.033)$ & $.045(.033)$ \\
\hline Multiple transitions & $-.33(2.05)$ & $.012(.031)$ & $.034(.034)$ \\
\hline \multicolumn{4}{|l|}{ Paternal incarceration } \\
\hline No incarceration (ref. group) & - & - & - \\
\hline Incarceration before child's birth & $2.28(1.56)$ & $-.013(.045)$ & $.054(.032)$ \\
\hline Incarceration after child's birth & $-1.56(1.98)$ & $.005(.026)$ & $.042(.033)$ \\
\hline \multicolumn{4}{|l|}{ Household employment status } \\
\hline Stably employed (ref. group) & - & - & - \\
\hline From out of work to employed & $-6.14(3.11)^{\dagger}$ & $.030(.026)$ & $.056(.033)^{\dagger}$ \\
\hline From employed to out of work & $-4.27(2.39) \dagger$ & $.038(.027)$ & $.039(.038)$ \\
\hline Stably workless & $-7.43(3.52)^{*}$ & $.019(.072)$ & $-.012(.039)$ \\
\hline In and out of work & $.25(3.22)$ & $-.004(.025)$ & $.032(.032)$ \\
\hline \multicolumn{4}{|l|}{ Housing tenure } \\
\hline Private market rental (ref. group) & - & - & - \\
\hline Public housing tenancy & $-4.87(1.89)^{*}$ & $-.019(.021)$ & $-.004(.023)$ \\
\hline Subsidised rental & $-4.57(3.07)$ & $.044(.025) \dagger$ & $.033(.047)$ \\
\hline Homeownership & $1.97(2.01)$ & $.011(.027)$ & $.033(.031)$ \\
\hline Other/shared tenancy & $-1.30(1.49)$ & $-.003(.020)$ & $-.009(.028)$ \\
\hline Household was ever evicted & $-1.15(2.04)$ & $.056(.036)$ & $-.013(.028)$ \\
\hline Index of local area relative disadvantage at birth & $-.06(0.68)$ & $.013(.010)$ & $-.006(.013)$ \\
\hline Index of local area relative disadvantage at year 5 & $-.80(0.67)$ & $.007(.005)$ & $.011(.010)$ \\
\hline Hardship & $.83(1.22)$ & $.026(.009)^{* *}$ & $.028(.008)^{* *}$ \\
\hline
\end{tabular}




\begin{tabular}{|c|c|c|c|}
\hline \multirow{2}{*}{ Variable } & Verbal score & Internalising problems & Externalising problems \\
\hline & b (SE) & b (SE) & b (SE) \\
\hline Nat. log of equivalised $\mathrm{HH}$ income & $1.46(0.43)^{* *}$ & $-.000(.007)$ & $.001(.007)$ \\
\hline Household size & $-.86(0.48)^{\dagger}$ & $.007(.010)$ & $.007(.008)$ \\
\hline Child was firstborn & $1.40(1.59)$ & $.012(.018)$ & $.002(.028)$ \\
\hline New sibling & $3.71(1.49)^{*}$ & $.001(.020)$ & $-.012(.017)$ \\
\hline Mother was not born in US & $-5.94(1.90)^{* *}$ & $.046(.047)$ & $-.010(.038)$ \\
\hline \multicolumn{4}{|l|}{ Mother's race/ethnicity } \\
\hline White (ref. group) & - & - & - \\
\hline Black & $-5.11(1.93)^{*}$ & $-.067(.015)^{* * *}$ & $-.006(.026)$ \\
\hline Hispanic & $-6.22(2.12)^{* *}$ & $.000(.025)$ & $.026(.036)$ \\
\hline Other race/ethnicity & $1.10(2.46)$ & $-.015(.048)$ & $-.028(.052)$ \\
\hline Mother's age & $.09(0.12)$ & $.002(.002)$ & $-.002(.003)$ \\
\hline Mother's level of education & $.87(0.47)^{\dagger}$ & $-.005(.006)$ & $-.003(.007)$ \\
\hline Mother's level of general health & $1.35(0.51)^{*}$ & $-.002(.008)$ & $-.011(.010)$ \\
\hline Mother depressed & $1.96(2.53)$ & $.032(.030)$ & $.035(.023)$ \\
\hline Child's biological sex is male & $-1.31(1.29)$ & $.010(.016)$ & $.033(.013)^{*}$ \\
\hline Child's age & $.04(0.35)$ & $.004(.004)$ & $-.007(.004) \dagger$ \\
\hline Child was born underweight & $-1.35(1.55)$ & $-.005(.021)$ & $.051(.031)$ \\
\hline Child's general health & $-.42(0.96)$ & $-.011(.010)$ & $-.002(.012)$ \\
\hline Constant & $82.04(20.18)^{* * *}$ & $-.049(.280)$ & $.776(.277)^{* *}$ \\
\hline$R^{2}$ & .38 & .11 & .09 \\
\hline Lowest F-test across Imputations ( $d f$ ) & $54 * * *(36)$ & $20 * * *(36)$ & $11^{* * *}(36)$ \\
\hline
\end{tabular}

$+p<.1, * p<.05 ; * * p<.01 ; * * * p<.00$ 
Behavioural outcomes show a different pattern of correlation, with fewer significant predictors in the final model. Financial hardship is positively associated with internalising problems. Black children have lower rates of internalising problem. Finally, similar to internalising problems, externalising behaviour problems are higher among children whose families face financial hardship. They are also higher among boys.

\section{Discussion}

Some residential mobility research treats events that co-occur with moves as 'nuisance factors' to be statistically controlled. However, these events contribute to both residential mobility and to child wellbeing. Moving appears to be part of a constellation of events and changes experienced by young children. Accounting for the breadth of events will be important for future research, and we find that of particular importance among the range of stressful circumstances are lack of parental employment, partnership transitions, paternal incarceration, unstable housing tenure and financial hardship.

These results resonate with Bronfenbrenner's ecological systems perspective, with its focus on the importance of proximal contexts for young children. Moving appears to be a response to both positive and negative circumstances as seen in the increased likelihood of moves with high levels of financial hardship as well as the somewhat increased likelihood of moves with high levels of income. Moving house at a young age is a normative step in the life course but one that may be enacted under difficult situations.

The importance of context is further highlighted in our models of child outcomes. We find support for our hypothesis that the association of the number of home moves with child outcomes appears to be entirely accounted for by the circumstances associated with moving and characteristics of families that do move. Before these factors are taken into account, the more children move in the early years, the worse their verbal skills and the more internalising and externalising problems they exhibit. The association with vocabulary is accounted for by family transitions in partnership and paternal incarceration, both of which generate more frequent mobility. These types of events also reduce the association of residential mobility with behaviour problems. For internalising behaviour, employment transitions account for a small part of the association with moving as does housing tenure. The association between number of moves and externalising problems is accounted for, in part, by transitions in family life, employment, hardship, and tenure and fully accounted for once the set of control variables is included. For all three outcomes, the impact of moving home on children appears to be due to the circumstances that give rise to the move, rather than moving by itself. These results are consistent with those reported by Gambaro and Joshi for the UK in this issue and consistent with past findings (Anderson, 2012; Wood, Halfon, Scarlata, Newacheck, \& Nessim, 1993 $)^{\text {ix }}$.

These findings have important implications for housing policy. A major concern in any housing policy change is whether it will allow families to stay in their homes or require them to move. Many recent policies in the US, including the federal Rental Assistance Demonstration program and local initiatives like New Jersey's Ethel Lawrence housing development, encourage moving as either an explicit or implicit feature (Blumgart 2015; Massey, Albright, Casciano, \& Derickson, 2013). Our finding that moves themselves are not harmful, at least for young children, might suggest to policymakers that concern for young children need not dictate whether policies should encourage housing stability or mobility. Rather, we suggest that policy makers distinguish between 'advantaging' and 'disadvantaging' moves (see Lupton, 2016, this issue), creating policies that facilitate the former and deter the latter. As for our findings that unemployment and economic hardship maintain an enduring impact on children even when controlling for other factors, this underscores the need for policymakers to maintain or develop responses to the negative underlying causes of moves.

While this study benefited from a rich array of measures and from a panel design, it is not without limitations. We have no direct measures of families' reasons for moving; nor, with the exception of controlling for evictions, do we measure involuntary moves. Desmond and Kimbro (2015) indicate that the report of eviction in the Fragile Families Study is likely 
to be an underestimate. In addition, forced or involuntary moves may occur without eviction: threats of legal action, rent increases above what is affordable, cut backs in housing subsidies, and the like, may all compel families to move house (Desmond \& Kimbro, 2015). Moreover, families may wish to move but may be unable to do so because of financial constraints. Some research suggests that even when families are not forced to move, high rent burdens damage children's wellbeing (Harkness \& Newman 2005; Newman \& Holupka 2014, but see Coley et al. 2013). Future research should investigate both the desire to move and reasons for moving (or staying put) as Lupton suggests in this issue.

This study was also conducted prior to the Great Recession, a period in which instability in employment, income, and housing increased. Effects of moving during those difficult economic times may differ from those in the period studied here when the economy was stronger. In addition, the housing and neighbourhood contexts that influence child wellbeing are themselves shaped by shifting housing policies and markets. The mortgage crisis of 2008 forced many foreclosed homeowners to move into rental units, hastening the decline of homeownership and the increase in renting. This housing instability is felt at the household-level as ontological insecurity (Giddens, 1984, 1991; Hiscock, Kearns, Macintyre, \& Ellway, 2001; Ross \& Squires, 2011), which refers to the sense that the material and social world are neither trustworthy nor constant. Coupled with increased economic uncertainty and hardship, growing housing instability may produce more difficulties for families and their young children in years to come.

\section{Acknowledgements}

This work was funded by the Eunice Kennedy Shriver National Institute of Child Health and Human Development (NICHD) grant 1R15HD065653-01 and by ESRC grant ES/K000438/1. We are grateful to Heather Joshi, William A. V. Clark, and the LLCS reviewers for comments on earlier versions of this paper.

\section{References}

Achenbach, T. M. (1992). Manual for the child behavior checklist 2-3 and 1992 profile. Burlington, VT: University of Vermont Department of Psychiatry.

Achenbach, T. M., \& Rescorla, L. A. (2000). Manual for the ASEBA preschool forms and profiles. Burlington, VT: University of Vermont, Research Center for Children, Youth \& Families.

Anderson, S. (2012). When moving may matter for children: An exploration of the role of time and place (Doctoral dissertation). Retrieved from ProQuest Dissertations and Theses. (UMI Number: 3541691)

Anderson, S., Leventhal, T., Newman, S., \& Dupéré, V. (2014). Residential mobility among children: A framework for child and family policy. Cityscape, 16(1), 5-36.

Astone, N. M., \& McLanahan, S. S. (1994). Family-structure, residential mobility, and school dropout: A research note. Demography, 31, 575-584. http://dx.doi.org/10.2307/2061791

Blumgart, J. (2015). The Obama administration is expanding a program to fix up public housing. The Nation, June 9.

Bronfenbrenner, U. (1977). Toward an experimental ecology of human development. American Psychologist, 32(7), 513. http://dx.doi.org/10.1037/0003-066X.32.7.513

Bronfenbrenner, U. (1986). Ecology of the family as a context for human development: Research perspectives. Developmental Psychology, 22(6), 723. http://dx.doi.org/10.1037/0012-1649.22.6.723

Bronfenbrenner, U. (2005). Making human beings human: Bioecological perspectives on human development. Thousand Oaks, CA: Sage Publications.

Bronfenbrenner, U., \& Evans, G. W. (2000). Developmental science in the 21st century: Emerging questions, theoretical models, research designs and empirical findings. Social Development, 9, 115-125.

http://dx.doi.org/10.1111/1467-9507.00114 
Bronfenbrenner, U., \& Morris, P. A. (1998). The ecology of developmental processes. In W. Damon \& R. M. Lerner (Eds.), Handbook of child psychology, Vol. 1: Theoretical models of human development (5th ed., pp. 993-1023). New York: Wiley.

Bronfenbrenner, U., \& Morris, P. A. (2006). The bioecological model of human development. In W. Damon \& R. M. Lerner (Eds.), Handbook of child psychology, Vol. 1: Theoretical models of human development (6th ed., pp. 793-828). New York: Wiley.

Brown, G. W., \& Harris, T. O. (1978). Social origins of depression: A study of psychiatric disorder in women. New York: Free Press.

Cicchetti, D., Rogosch, F. A., \& Toth, S. L. (1998). Maternal depressive disorder and contextual risk: Contributions to the development of attachment insecurity and behavior problems in toddlerhood. Developmental Psychopathology, 10(2), 283-300. http://dx.doi.org/10.1017/S0954579498001618

Clark, W. A. (2012). Moving and staying in Los Angeles neighborhoods: Money matters, but so does family composition. Cityscape, 14(3), 115-135.

Clark, W. A. (2016). Life events and moves under duress: Disruption in the life course and mobility outcomes. Longitudinal and Life Course Studies 7(3), 218-239. http://dx.doi.org/10.14301/llcs.v7i3.376.

Clark, W. A., \& Morrison, P. S. (2012). Socio-spatial mobility and residential sorting: evidence from a large-scale survey. Urban Studies, 49(15), 3253-3270. http://dx.doi.org/10.1177/0042098012442418

Clark, W. A., \& Davies Withers, S. (1999). Changing jobs and changing houses: Mobility outcomes of employment transitions. Journal of Regional Science, 39(4), 653-673. http://dx.doi.org/10.1111/0022-4146.00154

Coley, R. L., Leventhal, T., Lynch, A. D., \& Kull, M. (2013). Relations between housing characteristics and the well-being of low-income children and adolescents. Developmental Psychology, 49(9), 1775-1789. http://dx.doi.org/10.1037/a0031033

Conger, R. D., \& Elder, G. H. (1994). Families in troubled times: Adapting to change in rural America. New York, NY: Aldine de Gruyter.

Coulton, C., Theodos, B., \& Turner, M. (2009). Family mobility and neighborhood change: New evidence and implications from community initiatives. The Urban Institute.

Desmond, M. (2012). Eviction and the reproduction of urban poverty. American Journal of Sociology, 118(1), 88133. http://dx.doi.org/10.1086/666082

Desmond, M., Gershenson, C., \& Kiviat, B. (2015). Forced relocation and residential instability among urban renters. Social Service Review, 89(2), 227-262. http://dx.doi.org/10.1086/681091

Desmond, M., \& Kimbro, R. T. (2015). Eviction's fallout: Housing, hardship, and health. Social Forces, 94(1), 295324. http://dx.doi.org/10.1093/sf/sov044

Dohrenwend, B. P., \& Dohrenwend, B.S. (1969). Social status and psychological disorder. New York: John Wiley.

Duncan, G. J., Brooks-Gunn, J., \& Kato Klebanov, P. (1994). Economic deprivation and early childhood development. Child Development, 65, 296-318. http://dx.doi.org/10.2307/1131385

Dunn, L.M., \& Dunn, L.M. (1997). Examiner's manual for the Peabody picture vocabulary test, third edition. American Guidance Services, Inc.

Elder Jr., G. H., Johnson, M. K., \& Crosnoe, R. (2003). The emergence and development of life course theory. Springer US. http://dx.doi.org/10.1007/978-0-306-48247-2_1

Fitzmaurice, G. M., Laird, N. M., \& Ware, J. H. (2011). Applied longitudinal analysis. Hoboken, NJ: John Wiley \& Sons, Inc.

Gambaro, L., \& Joshi, H. (2016). Moving home in the early years: What happens to children in the UK? Longitudinal and Life Course Studies 7(3), 265-287. http://dx.doi.org/10.14301/Ilcs.v7i3.375

Geller, A., \& Franklin, A,W. (2014). Paternal incarceration and the housing security of urban mothers. Journal of Marriage and Family, 76, 411-427. http://dx.doi.org/10.1111/jomf.12098

Geller, A., Garfinkel, I., Cooper, C. E., \& Mincy, R. B. (2009). Parental incarceration and child well-being: Implications for urban Families. Social Science Quarterly, 90, 1186-1202.

http://dx.doi.org/10.1111/j.1540-6237.2009.00653.x 
Gershoff, E. T., Aber, J. L., Raver, C. C., \& Lennon, M. C. (2007). Income is not enough: Incorporating material hardship into models of income associations with parenting and child development. Child Development, 78(1), 70-95. http://dx.doi.org/10.1111/j.1467-8624.2007.00986.x

Giddens, A. (1984). The constitution of society. Berkeley: University of California Press.

Giddens, A. (1991). Modernity and self-identity: Self and society in the late modern age. Cambridge: Polity Press.

Harkness, J., \& Newman, S. J. (2005). Housing affordability and children's well-being: Evidence from the national survey of America's families. Housing Policy Debate, 16, 223-255. http://dx.doi.org/10.1080/10511482.2005.9521542

Hilbe, J. M. (2014). Modeling count data. New York: Cambridge University Press. http://dx.doi.org/10.1017/CBO9781139236065

Hiscock, R., Kearns, A., Macintyre, S., \& Ellway, A. (2001). Ontological security and psycho-social benefits from the home: Qualitative evidence on issues of tenure. Housing, Theory, \& Society, 18, 50-66. http://dx.doi.org/10.1080/14036090120617

Holmes, T. H., \& Rahe, R. H. (1967). The social readjustment rating scale. Journal of Psychosomatic Research, 11(2), 213-218. http://dx.doi.org/10.1016/0022-3999(67)90010-4

Jelleyman, T., \& Spencer, N. (2008). Residential mobility in childhood and health outcomes: A systematic review. Journal of Epidemiology and Community Health, 62, 584-592. http://dx.doi.org/10.1136/jech.2007.060103

Kessler, R.C., Andrews, G., Mroczek, D., Ustun, T.B., \& Wittchen, H.-U. (1998). The World Health Organization composite international diagnostic interview short form (CIDI-SF). International Journal of Methods in Psychiatric Research, 7(4), 171-185. http://dx.doi.org/10.1002/mpr.47

Kohen, D. E., Leventhal, T., Dahinten, V. S., \& McIntosh, C. N. (2008). Neighborhood disadvantage: Pathways of effects for young children. Child Development, 79, 156-169. http://dx.doi.org/10.1111/j.14678624.2007.01117.x

Long, L. (1992 $2_{\mathrm{a}}$ ). Changing residence: Comparative perspectives on its relationship to age, sex, and marital status. Population Studies, 46, 141-158. http://dx.doi.org/10.1080/0032472031000146056

Long, L. (1992b). International perspectives on the residential mobility of America's children. Journal of Marriage and the Family, 54, 861-869. http://dx.doi.org/10.2307/353167

Lupton, R. (2016). Housing policies and their relationship to residential moves for families with young children. Longitudinal and Life Course Studies 7(3), 288-301. http://dx.doi.org/10.14301/llcs.v7i3.377.

Lyons-Ruth, K., Brofman, E., \& Parsons, E. (1999). Atypical attachment in infancy and early childhood among children at developmental risk. IV. Maternal frightened, frightening, or atypical behavior and disorganized infant attachment patterns. Monograph of the Society for Research in Child Development, 64(3), 67-96. http://dx.doi.org/10.1111/1540-5834.00034

MacCallum, R.C., Zhang, S., Preacher, K.J., \& Rucker, D.D. (2002). On the practice of dichotomization of quantitative variables. Psychological Methods, 7, 19-40. http://dx.doi.org/10.1037/1082-989X.7.1.19

Massey, D. S., Albright, L., Casciano, R., Derickson, E., \& Kinsey, D. N. (2013). Climbing mount laurel: The struggle for affordable housing and social mobility in an American suburb. Princeton: Princeton University Press.

Masten, A. S., Herbers, J. E., Desjardins, C. D., Cutuli, J. J., McCormick, C. M., Sapienza, J. K., Long, J. D., \& Zelazo, P. D. (2012). "Executive function skills and school success in young children experiencing homelessness." Educational Researcher 41(9): 375-384. http://dx.doi.org/10.3102/0013189X12459883

Mehana, M., \& Reynolds, A. J. (2004). School mobility and achievement: A meta-analysis. Children and Youth Services Review, 26, 93-119. http://dx.doi.org/10.1016/j.childyouth.2003.11.004

Murphey, D., Bandy, T., \& Moore, K. A. (2012). Frequent residential mobility and young children's well-being. Child Trends Research Brief, 2012-02.

Newman, S. J., \& Holupka, C. S. (2014). Housing affordability and investments in children. Journal of Housing Economics, 24, 89-100. http://dx.doi.org/10.1016/j.jhe.2013.11.006 
Phillips, D. A., \& Shonkoff, J. P. (Eds.). (2000). From neurons to neighborhoods: The science of early childhood development. Washington D.C.: National Academies Press.

Phinney, R. (2013). Exploring residential mobility among low-income families. Social Service Review, 87, 780815. http://dx.doi.org/10.1086/673963

Pribesh, S., \& Downey, D. B. (1999). Why are residential and school moves associated with poor school performance?. Demography, 36, 521-534. http://dx.doi.org/10.2307/2648088

Reichman, N. E., Teitler, J. O., Garfinkel, I., \& McLanahan, S. S. (2001). Fragile families: Sample and design. Children and Youth Services Review, 23, 303-326. http://dx.doi.org/10.1016/S0190-7409(01)00141-4

Rubin, D. B. (1987). Multiple imputation for nonresponse in survey. New York: Wiley. http://dx.doi.org/10.1002/9780470316696

Rubin, D. B. (1996). Multiple imputation after 18+ years. Journal of the American Statistical Association, 91, 473489. http://dx.doi.org/10.1080/01621459.1996.10476908

Royston, P., \& White, I. R. (2011). Multiple imputation by chained equations (MICE): Implementation in Stata. Journal of Statistical Software, 45, 1-20. http://dx.doi.org/10.18637/jss.v045.i04

Ross, L. M., \& Squires, G. D. (2011). The personal costs of subprime lending and the foreclosure crisis: A matter of trust, insecurity, and institutional deception. Social Science Quarterly, 92, 140-163. http://dx.doi.org/10.1111/j.1540-6237.2011.00761.x

Sampson, R. J., \& Sharkey, P. (2008). Neighborhood selection and the social reproduction of concentrated racial inequality. Demography, 45(1), 1-29. http://dx.doi.org/10.1353/dem.2008.0012

Scanlon, E., \& Devine, K. (2001). Residential mobility and youth well-being: Research, policy, and practice issues. Journal of Sociology and Social Welfare, 28, 119-138.

Schluter, P. J., Ford, R. P. K., Mitchell, E. A., \& Taylor, B. J. (1998). Residential mobility and sudden infant death syndrome. Journal of Pediatrics and Child Health, 34, 432-437. http://dx.doi.org/10.1046/j.14401754.1998.00268.x

Schmitt, S. A., Finders, J. K., \& McClelland, M. M. (2015). Residential mobility, inhibitory control, and academic achievement in preschool. Early Education and Development, 26, 189-208. http://dx.doi.org/10.1080/10409289.2015.975033

Stokols, D., Shumaker, S. A., \& Martinez, J. (1983). Residential mobility and personal well-being. Journal of Environmental Psychology, 3, 5-19. http://dx.doi.org/10.1016/S0272-4944(83)80018-8

Stoneman, Z., Brody, G. H., Churchill, S. L., \& Winn, L. L. (1999). Effects of residential instability on head start children and their relationships with older siblings: Influences of child emotionality and conflict between family caregivers. Child Development, 70, 1246-1262. http://dx.doi.org/10.1111/1467-8624.00090

South, S. J., Crowder, K. D., \& Trent, K. (1998). Children's residential mobility and neighborhood environment following parental divorce and remarriage. Social Forces, 77(2), 667-693. http://dx.doi.org/10.1093/sf/77.2.667

Thoits, P. A. (1983). Dimensions of life events that influence psychological distress: An evaluation and synthesis of the literature. In Howard Kaplan (ed.), Psychosocial Stress: Trends in Theory and Research (pp. 33103). New York: Academic Press. http://dx.doi.org/10.1016/B978-0-12-397560-7.50007-6

Tunstall, H., Pickett, K., \& Johnsen, S. (2010). Residential mobility in the UK during pregnancy and infancy: Are pregnant women, new mothers and infants 'unhealthy migrants'? Social Science \& Medicine, 71(4), 786798. http://dx.doi.org/10.1016/j.socscimed.2010.04.013

Turney, K., \& Harknett, K. (2009). Neighborhood disadvantage, residential stability, and perceptions of instrumental support among new mothers. Journal of Family Issues, 31(4), 499-524. http://dx.doi.org/10.1177/0192513X09347992

U.S. Census Bureau. (2001). Geographical mobility: March 1999 to March 2000. Washington, DC: U.S. Census Bureau. 
van Buuren, S., Brand, J. P. L., Groothuis-Oudshoorn, C. G. M., \& Rubin, D. B. (2006). Fully conditional specification in multivariate imputation. Journal of Statistical Computation and Simulation, 76, 10491064. http://dx.doi.org/10.1080/10629360600810434

Winslow, E. B., \& Shaw, D. S. (2007). Impact of neighborhood disadvantage on overt behavior problems during early childhood. Aggressive Behavior, 33, 207-219. http://dx.doi.org/10.1002/ab.20178

Wodtke, G. T., Harding, D. J., \& Elwert, F. (2011). Neighborhood effects in temporal perspective: The impact of long-term exposure to concentrated disadvantage on high school graduation. American Sociological Review, 76, 713-736. http://dx.doi.org/10.1177/0003122411420816

Wood, D., Halfon, N., Scarlata, D., Newacheck, P., \& Nessim, S. (1993). Impact of family relocation on children's growth, development school function, and behavior. Journal of American Medical Association, 270, 1334-1338. http://dx.doi.org/10.1001/jama.1993.03510110074035

Yeung, W. J., Linver, M. R., \& Brooks-Gunn, J. (2002). How money matters for young children's development: Parental investment and family processes. Child Development, 73(6), 1861-1879. http://dx.doi.org/10.1111/1467-8624.t01-1-00511

Ziol-Guest, K. M., \& McKenna, C. C. (2014). Early childhood housing instability and school readiness. Child Development, 85, 103-113. http://dx.doi.org/10.1111/cdev.12105

\section{Endnotes}

${ }^{\mathrm{i}}$ This article uses data from the Fragile Families and Child Wellbeing Study, as does ours. Given different model specifications, our analyses do not replicate these results. We discuss this further in endnote ix.

ii If the mother had twins or triplets, only one child was followed. This was the case for 95 of the 4,898 mothers interviewed in the baseline wave.

iii The differences between our analytic samples and the full sample were all under the $2 \%$ range. The largest difference referred to the race/ethnicity variable, which in the analytic samples overrepresented Black mothers by $1.7 \%$ and mothers of Other race/ethnicity, who instead are underrepresented by $1.6 \%$.

${ }^{\text {iv }}$ An alternative viable method for our study is Multiple Imputation by Chained Equations (MICE) where the missing values are filled in through a series of linked (i.e. chained) univariate imputation models run iteratively. In MICE both 'imputed' and 'imputing' variables may have missing information and each one of them is imputed using its own imputation model (i.e. its own posterior predictive distribution; see Royston \& White, 2011). The imputation then proceeds according to the increasing level of missing information, starting from the variable with the lowest amount of missing values. Due to the theoretical weakness of this approach (van Buuren, Brand, Groothuis-Oudshoorn \& Rubin, 2006) and the modest amount of missing information in our analytic sample (between one-15 cases had incomplete data on seven variables, less than $5 \%$ on two measures, and $10.7 \%$ on one), we preferred the MI univariate method with passive approach. The Multivariate Normal (MVN), another imputation method, was not appropriate for our study because of its normal distribution assumption used in the data augmentation, which is not tenable for the categorical variables we used in the analyses.

${ }^{\mathrm{v}}$ The baseline measure had four rather than five categories because sharers/others were included both homeowners and market renters in the survey item. To create this fifth category we first reallocated in it those cases that had not moved in following waves (i.e. the stayers) then, for the remaining cases we proceeded with conditional multiple imputation.

${ }^{v i}$ We evaluated the distribution of this measure (which ranged from 0-20) and checked for linearity of the parameters, using dummy variables to represent each number of moves. Based on these analyses, we topcoded number of moves at five (where a total of $2.2 \%$ of cases had experienced 6-20 residential moves).

${ }^{\text {vii }}$ As measured by the Comprehensive International Diagnostic Interview Short Form (CIDI-SF) (Kessler, Andrews, Mroczek, Ustun, \& Wittchen, 1998). 
viii In this baseline model we add the dummy 'single mother at birth' to further control for survey design effect. Its statistical adjustment is then picked up in following models once we introduce the variable on parental structure.

${ }^{\text {ix }}$ It is important to note that our findings differ from those reported by Ziol-Guest and McKenna (2014) who used the same dataset. They found that more than three moves, coupled with childhood poverty, was most consequential for child attention problems, internalising behaviour and externalising behaviour. We chose to not discretize number of moves because our analyses showed that there is a linear association (in the parameters) between moves (up to five and more) and child outcomes. We also chose to use the full range of information of family economic circumstances (including level of hardship and income). MacCallum and colleagues (2002) caution strongly against the practice of converting continuous measures into discrete variables, especially when testing for interaction effects. We were unable to detect an interaction of number of moves and family income (or hardship) using continuous measures of these variables. 